\title{
Toxicity of anthelmintic drugs (fenbendazole and flubendazole) to aquatic organisms
}

\author{
Marta Wagil • Anna Białk-Bielińska • Alan Puckowski • Katarzyna Wychodnik • \\ Joanna Maszkowska • Ewa Mulkiewicz • Jolanta Kumirska • Piotr Stepnowski • \\ Stefan Stolte
}

Received: 23 March 2014 / Accepted: 20 August 2014 / Published online: 6 September 2014

(C) The Author(s) 2014. This article is published with open access at Springerlink.com

\begin{abstract}
Flubendazole (FLU) and fenbendazole (FEN) belong to benzimidazoles - pharmaceuticals widely used in veterinary and human medicine for the treatment of intestinal parasites as well as for the treatment of systemic worm infections. In recent years, usage of these drugs increased, which resulted in a larger contamination of the environment and possible negative effects on biota. Hence, in our research, we investigated an aquatic ecotoxicity of these pharmaceuticals towards: marine bacteria (Vibrio fischeri), green algae (Scenedesmus vacuolatus), duckweed (Lemna minor) and crustacean (Daphnia magna). Ecotoxicity tests were combined with chemical analysis in order to investigate the actual exposure concentration of the compounds used in the experiment as well as to stability and adsorption studies. As a result, study evaluating sensitivity of different aquatic organisms to these compounds and new ecotoxicological data is presented. The strongest negative impact of FLU and FEN was observed to D. magna.
\end{abstract}

Keywords Ecotoxicity $\cdot$ Flubendazole $\cdot$ Fenbendazole $\cdot$ Aquatic species $\cdot$ Anthelmintic drugs $\cdot$ Benzimidazoles

Responsible editor: Philippe Garrigues

M. Wagil · A. Białk-Bielińska $(\bowtie) \cdot$ A. Puckowski •

K. Wychodnik J. Maszkowska $\cdot$ E. Mulkiewicz J. Kumirska

P. Stepnowski $\cdot$ S. Stolte

Department of Environmental Analysis, Faculty of Chemistry, University of Gdańsk, ul. Wita Stwosza 63, 80-308 Gdańsk, Poland

e-mail: abialk@chem.univ.gda.pl

S. Stolte

UFT Center for Environmental Research and Sustainable

Technology, University of Bremen, Leobener Straße,

D-28359 Bremen, Germany

\section{Introduction}

Flubendazole (FLU) and fenbendazole (FEN) — belonging to benzimidazoles group - are anthelmintic drugs widely used in veterinary medicine in order to treat diseases in agriculture and aquaculture and also in human medicine (Danaher et al. 2006). Being excreted from the body with faeces and urine, they reach environment via different routes. According to literature, residues of FLU were found in the leachate from agricultural manure to drainage waters reaching values of up to $300 \mathrm{ng} \mathrm{L}^{-1}$ (Weiss et al. 2008) as well as in influent (19.9$\left.89.7 \mu \mathrm{g} \mathrm{L}^{-1}\right)$ and effluent (55.0-671.0 $\mathrm{ng} \mathrm{L}^{-1}$ ) wastewater from the pharmaceutical industry (Van De Steene and Lambert 2008). Moreover, they were also detected in the surface waters (the Llobregat River, Spain) at the concentrations up to $1.32 \mathrm{ng} \mathrm{L}^{-1}$ (Zrnčić et al. 2014). Hence, these compounds as well as other pharmaceuticals have been classified as emerging environmental contaminants for almost 15 years now. Their structural formulas and selected physicochemical properties are presented in Table 1. Special attention should be paid to the high values of octanol-water partition coefficients of FLU (2.91 (Horvat et al. 2012)) and FEN (3.93 (Mottier et al. 2003)) which can influence their environmental fate and bioavailability. These chemicals are designed to have a specific mode of action which is binding to $\beta$-tubulin and inhibition of microtubule formation in the intestinal cells inducing a decreased glucose uptake and starving of the parasites (Martin 1997). Since microtubules serve a variety of important functions in animal, plant, fungi and some bacterial cells make FLU and FEN to be evaluated for potential effects on aquatic flora and fauna. Even though the health-risk assessment of pharmaceutical compounds regarding their toxicity is available, little is known about the ecotoxicological 
Table 1 Structural formulas and selected physicochemical properties of flubendazole (FLU) and fenbendazole (FEN)

Compound Chemical structure

${ }^{a}$ Horvat et al. 2012

${ }^{\mathrm{b}}$ Nobilis et al. 2007

${ }^{\mathrm{c}}$ Mottier et al. 2003

${ }^{\mathrm{d}}$ Santana Rodríguez et al. 2010

effects on non-target organisms. Toxicity of many other pharmaceuticals (with special emphasis to veterinary drugs) has been demonstrated in various aquatic organisms (e.g.: Tišler and Kožuh Eržen 2006; Park and Choi 2008; Santos et al. 2010; Białk-Bielińska et al. 2011; Kołodziejska et al. 2013).

Aquatic organisms are particularly important targets, as they are exposed via wastewater residues over their whole life. Once inside the organism, the pollutant may promote a variety of effects, ranging from cellular impairment to lethality. As Escher has highlighted the consideration of underlying molecular mechanisms and modes of toxic action on different levels of biological organization is crucial to enhance the understanding of the effects of pollutants on living systems (Escher 2001). However, such studies are very limited.

There are only few literature data on the ecotoxicity of FLU and FEN towards limited number of aquatic species. From the species selected to our study, this includes only studies on Daphnia magna and Vibrio fischeri (Hoechst-Roussel AgriVet 1995; Oh et al. 2006). Moreover, these ecotoxicity tests have not been performed in combination with chemical analysis, which according to Garcia-Galán et al., enables to acquire a complete view of the exposure and the risk posed by these pollutants by the simple determination the chemical composition of the sample (García-Galán et al. 2009). Generally, there is no data available on the toxicity of FLU and FEN to green algae as well as to duckweed.

For all the above-mentioned reasons, the main aim of this study was to evaluate the ecotoxicity of FEN and FLU towards four aquatic organisms representing different levels of biological organization: luminescent marine bacteria (Vibrio fischeri), limnic unicellular green algae (Scenedesmus vacuolatus), duckweed (Lemna minor) and crustacean (Daphnia magna). This aim was achieved by the following:

- By performing ecotoxicological tests in combination with instrumental analysis which not only increase the reliability of the obtained ecotoxicological data but also enables to acquire a complete view of the exposure (bioavailability) and hence the risk posed by the pollutants. This aspect is very crucial as, due to the different physicochemical properties of chemicals (such as water solubility), their nominal concentration in the tests can essentially differ from the real one, which leads to underestimation of the hazard posed by the tested substances.

- By performing additional chemical studies and calculations in the case of the most sensitive organism (D. magna). These experiments were aimed at better understating of the reason for the observed toxicity. The investigation included determining the fate of the substance during the test conditions (stability and adsorption studies), as well as distinguishing the specific or nonspecific mode of toxic action of these compounds by applying the baseline toxicity model. The reason for this is the fact that the observed toxicity of a chemical is not necessarily associated with its parent form, but rather its degradation products - which can be produced under the test conditions (e.g. by hydrolysis or photolysis) and can be even more toxic. Moreover, also adsorption of chemicals on tests vessels is very important, as it can decrease the concentration of the chemical during the test, hence lowering the toxicity.

Although such studies are nowadays recommended, they are still limited. 


\section{Materials and methods}

All the data presented in our study were obtained according to internationally/nationally accepted test guidelines (e.g. OECD, ISO, DIN) or their modified versions.

\section{Chemicals}

FLU and FEN were purchased from Santa Cruz Biotechnology Inc. (Heidelberg, Germany). Acetonitrile (ACN), dimethyl sulfoxide (DMSO) and salts used for preparing culture media were supplied from Sigma-Aldrich (Steinheim, Germany).

\section{Standard stock solutions}

The standard stock solutions of FLU and FEN (500 mg L ${ }^{-1}$ ) were prepared separately by dissolving them in DMSO. These solutions were stored at above $18{ }^{\circ} \mathrm{C}$ (melting point of DMSO), in a dark and dry place. Stock solutions for ecotoxicity testing were prepared by dissolving standard stock solution in media solutions used in each ecotoxicity test.

\section{Luminescent inhibition assay with marine bacteria}

The toxicity test based on $V$. fischeri was done using the LCK 482 test kit (Dr Lange GmbH, Germany). The 30-min standard bioluminescence inhibition assay was carried out according to a modified DIN 38412-L34 protocol (1991). The tests were carried out three times for each substance with two parallel replicates in each test. At least four organic solventfree controls (containing only medium: $2 \% \mathrm{NaCl}$ solution, phosphate-buffered) and two solvent controls (containing $0.06 \%$ DMSO in medium) were used during each test. The tests were performed at $15{ }^{\circ} \mathrm{C}$ using thermostats (LUMIStherm, Dr Lange GmbH, Germany). The luminescence was measured with a luminometer (LUMIStox 300, Dr Lange GmbH, Germany). The freeze-dried bacteria were rehydrated according to the test protocol; then, $500 \mu \mathrm{L}$ aliquots of the bacteria solution were pre-incubated for $15 \mathrm{~min}$ at $15{ }^{\circ} \mathrm{C}$. After the initial luminescence had been measured, $500 \mu \mathrm{L}$ of the diluted samples were added. The bioluminescence was measured again after an incubation time of $30 \mathrm{~min}$. The relative toxicity of the samples was expressed as a percentage inhibition compared to the controls.

Reproduction inhibition assay with limnic green algae S. vacuolatus

A synchronized culture of the green algae $S$. vacuolatus (strain 211-15, SAG (Culture Collection of Algae), Universität Göttingen, Germany) was used for this assay. The stock culture was grown under photoautotrophic conditions at $28^{\circ} \mathrm{C}\left( \pm 0.5^{\circ} \mathrm{C}\right)$ in an inorganic, sterile medium (pH 6.4) with saturating white light (22 to $33 \mathrm{klx}$, Lumilux Daylight L 36 W-11 and Lumilux Interna L 36 W-41, Osram, Berlin, Germany). The cells were aerated with $1.5 \mathrm{vol} \% \mathrm{CO}_{2}$ and synchronized using a 14- to 10-h light-darkness cycle. The stock culture was diluted every day to a cell density of $5 \times$ $10^{5}$ cells $\mathrm{mL}^{-1}$. This test is a modified version of the assay described by Altenburger et al. (1990), and its sensitivity is comparable to the standardized 72-h test (ISO Guideline 8692 1989).

The toxicity tests started with autospores. The algae were exposed to the test substances for one growth cycle $(24 \mathrm{~h})$. The endpoint of this assay is the inhibition of algal reproduction, measured as the inhibition of population growth. Cell numbers were determined with a Coulter Counter Z2 (Beckmann, Nürnberg, Germany). The tests were performed in sterilized glass tubes, the algae were stirred throughout the 24-h test period, and the test conditions were the same as for the stock culture except for the $\mathrm{CO}_{2}$ source. Here, $150 \mu \mathrm{L}$ of $\mathrm{NaHCO}_{3}$ solution was added to each test tube. The methods of stock culturing and testing are described in detail by Faust et al. (2001). Growth inhibition was calculated using the cell counts of the treated samples in relation to the untreated controls. Six organic solvent-free controls (containing only medium) and six solvent controls (containing $0.2 \%$ DMSO in medium) were used for each assay. The tests were performed using six different concentrations in two replicates of every compound and each test was repeated three times.

\section{Growth inhibition assay with duckweed}

The growth inhibition assay with $L$. minor was performed according to a modified version of the test protocol described in detail by Drost et al. (2007). The plants were grown in open Erlenmeyer flasks in sterilized Steinberg medium (pH 5.5 0.2 ) in a climate chamber with a constant temperature of $25 \pm$ $2{ }^{\circ} \mathrm{C}$. To exclude $\mathrm{pH}$ effects on plant growth, the $\mathrm{pH}$ was checked at the beginning and end of the test. Based on control sample evaluation, the $\mathrm{pH}$ changes did not affect growth inhibition. The chamber was illuminated continuously with a maximum of $6 \mathrm{klx}$. The assays were performed on six-well cell culture plates (Greiner Bio-One GmbH, Frickenhausen, Germany). The tests were performed using six different concentrations in three replicates of every compound and each test was repeated three times. Six organic solvent free controls (containing only medium) and six solvent controls (containing $0.2 \%$ DMSO in medium) were used in each test. The test started with one plant consisting of three duckweed fronds, and the measured endpoint was the inhibition of the growth rate determined by the frond area $\left(\mathrm{mm}^{2}\right)$, which was calculated for the treated plants in relation to the untreated controls. The frond area was detected using a Scanalyzer from Lemnatec GmbH (Würselen, Germany). 
Growth inhibition assay with D. magna

The 48-h acute immobilization test with D. magna was assessed using the commercially available Daphtoxkit F (MicroBioTest Incorporation, Gent, Belgium), referred to OECD guideline 202 (2004). The detailed description of this assay is given in the supplier's standard operational procedure (MicroBioTest Inc and Daphtoxkit 1996). The tests with neonates less than $24-\mathrm{h}$ old, obtained by the hatching of ephippia, were performed at $20{ }^{\circ} \mathrm{C}$ in the dark. Five pre-fed animals were incubated with the toxicants in a volume of $10 \mathrm{~mL}$ of mineral medium in the plastic plates. In each test, five different concentrations of the test substance were investigated in five parallels and five solvent-free controls (medium) as well as five solvent controls (containing 0.015\% DMSO in medium for FLU and $0.01 \%$ DMSO in medium for FEN). All the experiments were performed in two parallel replicates and repeated twice. The numbers of immobilized organisms were checked after 24 and $48 \mathrm{~h}$. The sensitivity of the organisms to $\mathrm{K}_{2} \mathrm{Cr}_{2} \mathrm{O}_{7}$ was checked routinely once a new batch of organisms was obtained.

\section{Effect data modeling}

Dose-response curve parameters and plots were obtained using the drift package (version 0.05-95) for the $\mathrm{R}$ language and environment for statistical computing (www.r-project.org).

Instrumental analysis

In order to determine the soluble fraction of the investigated compound in biological media, HPLC-DAD analysis was performed. VWR Hitachi HPLC-DAD systems (containing the L-2130 HTA-pump, L-2130 degasser, L-2200 autosampler, L-2300 column oven, L-2450 diode arraydetector and the EZChrom Elite software, VWR, Darmstadt, Germany) was used. The separation was performed on Gemini $\mathrm{C}_{18}$ column $(150 \times 4.6 \mathrm{~mm}$ I.D., $5 \mu \mathrm{m}$ pore size, Phenomenex Inc., Torrance, CA). A mixture of A-ACN and $\mathrm{B}-\mathrm{H}_{2} \mathrm{O}$ was used as a mobile phase (gradient conditions, $30 \%$ $\mathrm{A}$ in $0 \mathrm{~min}, 60 \% \mathrm{~A}$ in $5 \mathrm{~min}$ and $30 \% \mathrm{~A}$ in $10 \mathrm{~min})$. The injection volume of the sample was $50 \mu \mathrm{L}$. A detection wavelength of $300 \mathrm{~nm}$ was used for the quantification. The analysis time was $15 \mathrm{~min}$.

The concentrations of stock solution of FLU and FEN in media solutions used in four ecotoxicity tests were as follows: $1 \mathrm{mg} \mathrm{L}{ }^{-1}$ for $L$. minor and $S$. vacuolatus (the solution consisted $0.2 \%$ DMSO), $0.05 \mathrm{mg} \mathrm{L}^{-1}$ (0.01\% DMSO) for FEN and $0.075 \mathrm{mg} \mathrm{L}^{-1}(0.015 \%$ DMSO) for FLU for D. magna and $0.3 \mathrm{mg} \mathrm{L}^{-1}$ for $V$. fischeri (0.06\% DMSO). In order to calculate the bioavailability, the peak area of the signals obtained from the analysis of the above-mentioned mixtures were compared to the peak area of the signals obtained from the analysis of the same concentrations of FLU and FEN prepared in ACN.

Chemical stability and adsorption studies

As strong negative effect of the tested compounds was observed on D. magna (see "Toxicity tests") additional experiments (chemical stability and adsorption studies) were performed. These assays were performed in two types of vessels: in a plastic (polycarbonate) and a glass beaker. Each vessel was filled with $10 \mathrm{~mL}$ of the substance solution prepared in D. magna test medium. For FEN and FLU, the concentration used in this test was 0.05 and $0.075 \mathrm{mg} \mathrm{L}^{-1}$, respectively, which was the highest concentration used in the standard test with organism. All the samples were kept in the same condition as during the test with D. magna. The test was performed in darkness in $20^{\circ} \mathrm{C}$. Samples were collected from each vessel within specific time intervals (after 0, 20, 24, 43 and $48 \mathrm{~h}$ ) and analyzed using HPLC-DAD technique (parameters described in "Instrumental analysis"). Moreover, samples were divided into two groups: mix and not mixed before sampling. Each sample was prepared in duplicate.

\section{Baseline toxicity}

In order to evaluate specific or non-specific mode of action, we used below equations (Escher and Hermens 2002):

$\log K \mathrm{mw}=0.90 \log K$ ow +0.521

$\operatorname{logEC} 50(M)=-0.77 \log K \mathrm{mw}-1.89$

$\frac{\text { EC50 (baseline) }}{\text { EC50 (experimental) }}=\mathrm{TR}$

where $K_{\mathrm{mw}}$ is membrane-water partition coefficient, $K_{\mathrm{ow}}$ is octanol-water partition coefficient, $\mathrm{EC}_{50}$ - half maximal effective concentration, $\mathrm{M}-$ molar concentration and $\mathrm{TR}$ - toxic ratio.

\section{Results and discussion}

Instrumental analysis

Special emphasis should be placed on the importance of understanding the interplay between environmental chemistry and toxicology, thereby linking the concepts of bioavailability and the mechanism of ecotoxicity (Escher et al. 1997). Thus, 
combining chemical analysis with ecotoxicological tests can results with obtaining valuable data.

For this purpose, fully optimized and validated method for the determination of FEN and FLU has been applied. This was validated using working calibration standard solutions according to the procedures described in our previous studies (Migowska et al. 2012). The obtained validation parameters were as follows: the accuracy for FLU 95.3-102.5 \% and for FEN 97.0-106.1 \%, the precision described by relative standard deviation (RSD) was for FLU between 1.5 and $5.1 \%$ and for FEN 1.2 and $4.6 \%$. The limit of quantification (LOQ) was $0.02 \mathrm{mg} \mathrm{L}^{-1}$ and the limit of detection (LOD) was $0.007 \mathrm{mg} \mathrm{L}^{-1}$ for both compounds. The correlation coefficient $\left(R^{2}\right)$ amount to 0.9996 for FLU and 0.9987 for FEN.

\section{Evaluation of soluble fraction of FEN and FLU in biological media}

The deviation between nominal and real concentration of the test compounds in the media of our test systems has been tested via instrumental analysis to avoid misinterpretation of bioavailability and hence the obtained ecotoxicological data.

This aspect was crucial for FEN and FLU which have a low water solubility (Table 1). The standard stock solutions $\left(500 \mathrm{mg} \mathrm{L}^{-1}\right)$ prepared in DMSO were diluted in each biological media to concentrations mentioned in "Effect data modeling". The addition of DMSO for L. minor and S. vacuolatus was $0.2 \%, 0.06 \%$ for $V$. fischeri and $0.015 \%$ for FLU and $0.01 \%$ for FEN for D. magna.

Nevertheless, this percentage of DMSO did not affect the organisms used in the tests, which was proved by testing the effect of control samples containing the same amount of DMSO in medium.

Results presenting the percentage of soluble fraction of FLU and FEN in biological media are presented in Table 2. These analyses indicate deviations (from $-1.6 \%$ for $D$. magna up to $-24.3 \%$ for $L$. minor for FLU and $-4.4 \%$ for D. magna up to $25.6 \%$ for $S$. vacuolatus for FEN) between nominal and measured concentrations of stock solutions containing

Table 2 Percentage of soluble fraction of examined compounds in biological media

\begin{tabular}{lllll}
\hline Compound & \multicolumn{4}{l}{ Percentage of soluble fraction $[\%]$ (standard deviation) } \\
\cline { 2 - 5 } & L. minor & S. vacuolatus & D. magna & V. fischeri \\
\hline FLU & $75.7(0.2)$ & $78.2(1.3)$ & $98.4(0.5)$ & $96.1(0.1)$ \\
FEN & $75.0(1.0)$ & $74.4(0.3)$ & $95.6(1.5)$ & $83.0(0.2)$ \\
\hline
\end{tabular}

biological media. The nominal concentration for D. magna as well as for $V$. fischeri tests can be considered as the bioavailable fraction within the toxicity tests. However, results for L. minor and S. vacuolatus test medium would indicate underestimating the real toxicity if it would be exactly determined.

Chemical stability and adsorption studies

Due to observed strong negative effect of the tested compounds to D magna (see "Toxicity tests"), additional stability and adsorption experiments were performed. The stability of FLU and FEN under the test conditions as well as possible adsorption of these drugs to plastic in comparison to the glass vessels was investigated over time (from time 0 to $48 \mathrm{~h}$ ) to address two questions: (i) whether observed effects can be attributed to the parent compound or due to degradation products formed under test conditions; (ii) whether very narrow concentration range between which for all organisms effect is observed (effect $100 \%$ ) or no effect is observed (effect $0 \%$ ) is influenced by adsorption of these chemicals to the surface of the vessels used in the D. magna toxicity test. A decrease in concentration of the tested compounds could be proven in particular when polycarbonate vessel is used (Fig. 1). The mixing procedure before sampling was of minor importance. Since the elimination under such test conditions was low (maximal $11 \%$ ), the obtained ecotoxicological data have not been recalculated.

\section{Toxicity tests}

In Table 3, $\mathrm{EC}_{50}$ values obtained in all ecotoxicity tests and for reference substances: atrazine and potassium dichromate are presented.

D. magna was the most sensitive aquatic organism towards investigated drugs (for FEN EC $5048 \mathrm{~h}=19 \mu \mathrm{g} \mathrm{L}^{-1}$ and for FLU $\left.\mathrm{EC}_{5048 \mathrm{~h}}=45 \mu \mathrm{g} \mathrm{L}^{-1}\right)$. These values are in agreement with $\mathrm{Oh}$ et al. (2006) who presented the $\mathrm{EC}_{50 \mathrm{FEN}}=16.5 \mu \mathrm{g} \mathrm{L}{ }^{-1}$ and $\mathrm{EC}_{50 \mathrm{FLU}}=66.5 \mu \mathrm{g} \mathrm{L}{ }^{-1}$ as well as with Hoechst-Roussel AgriVet (1995) who presented the $\mathrm{EC}_{50}$ only for FEN in the value of $12 \mu \mathrm{g} \mathrm{L}^{-1}$. No adverse effect on growth of algae $S$. vacuolatus and duckweed L. minor as well as to the luminescence of marine bacteria $V$. fischeri up to the highest tested concentration. Since already these concentrations exceed those found in the environment, we did not perform further experiments with the higher concentration range (Weiss et al. 2008; Van De Steene and Lambert 2008). The toxicity of FEN and FLU towards L. minor and algae $S$. vacuolatus is reported for the first time. However, such difference in sensitivity between algae and daphnids in acute toxicity tests was reported before for other group of pharmaceuticals, however also used as anthelmintic drug-abamectin (Tišler and Kožuh Eržen 2006). EC 50 values obtained for algae 

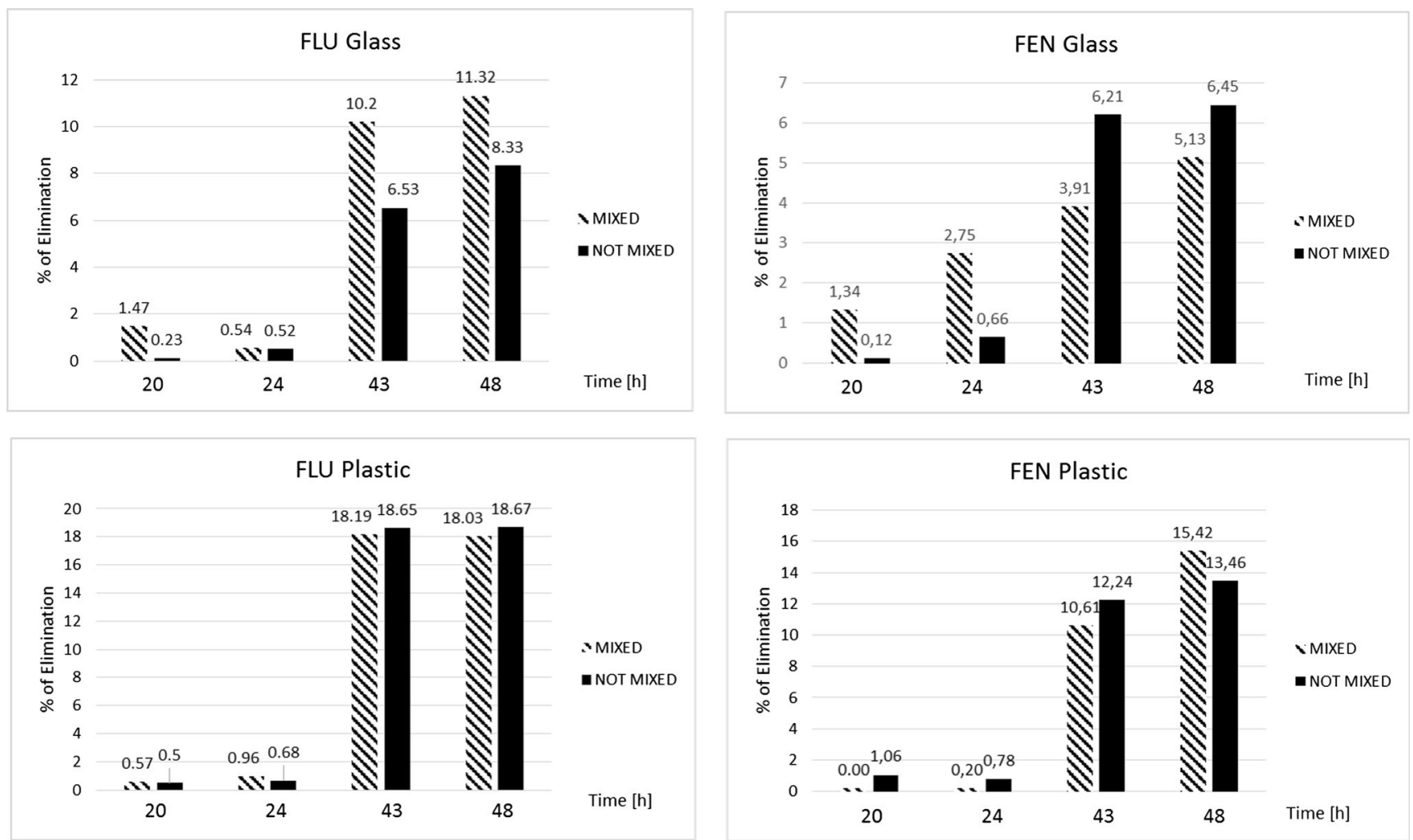

Fig. 1 Results obtained during chemical and adsorptions studies (the percent of elimination is referring to the percet that has been eliminated from the solution)

Scenedesmus subspicatus $\left(\mathrm{EC}_{50} 72 \mathrm{~h}=4.4 \mathrm{mg} \mathrm{L}^{-1}\right)$ and D. magna $\left(\mathrm{EC}_{50} 48 \mathrm{~h}=0.25 \mu \mathrm{g} \mathrm{L}^{-1}\right)$ differed five orders of magnitude.

Also $V$. fischeri was much less sensitive to the studied benzimidazole anthelmintics than D. magna. It was reported that flubendazole and fenbendazole inhibited bacterial metabolism after 15 min of incubation by $50 \%$ at similar concentrations 0.853 and $0.798 \mathrm{mg} \mathrm{L}^{-1}$ (Oh et al. 2006). These results are in agreement with our study since we did not observe any toxic effect to $V$. fischeri at concentration $0.3 \mathrm{mg} \mathrm{L}^{-1}$. Studies

Table 3 The $\mathrm{EC}_{50}$ values for FLU and FEN obtained during experiments and toxicity of references compounds

\begin{tabular}{lllll}
\hline \multirow{2}{*}{ Compound } & \multicolumn{4}{l}{$\mathrm{EC}_{50}$ (confidence interval) $\left[\mathrm{mg} \mathrm{L}^{-1}\right]$} \\
\cline { 2 - 5 } & D. magna & V.fischeri & L.minor & S.vacuolatus \\
\hline FLU & $0.045(0.043-0.046)$ & $>0.3$ & $>1$ & $>1$ \\
FEN & $0.019(0.018-0.020)$ & $>0.3$ & $>1$ & $>1$ \\
Atrazine & $35.5^{\mathrm{a}}$ & $69.4^{\mathrm{a}}$ & $0.188^{\mathrm{b}}$ & $0.039^{\mathrm{c}}$ \\
$\mathrm{K}_{2} \mathrm{Cr}_{2} \mathrm{O}_{7}$ & $0.6-2.1^{\mathrm{d}}$ & - & - & - \\
\hline
\end{tabular}

${ }^{\text {a }}$ Palma et al. 2008

${ }^{\mathrm{b}}$ Teodorović et al. 2012

${ }^{\mathrm{c}}$ Faust et al. 2001

${ }^{\mathrm{d}}$ ISO Guideline 63411996 concerning their ecotoxicity to $V$. fischeri and D. magna, although are in agreement with the literature data, provide new insights, thanks to the results from the chemical analysis and prove high reliability of the existing and newly obtained data.

Apart from difference in species, sensitivity between the microbe and the invertebrate lower bioavailability of the tested benzimidazoles in the osmotically adjusted bacterial media was suggested as a possible cause of observed much lower toxicity of studied pharmaceuticals in V. fischeri in comparison to $D$. magna. This can be also an effect of other mode of toxic action of these pharmaceuticals in the selected organisms. However, chronic as well as mixture toxicity cannot be excluded (Wollenberger et al. 2000; Cleuvers 2003; Alexy et al. 2004); hence, further studies should be performed in the future.

High toxicity of FEN and FLU to D. magna was also reported by $\mathrm{Oh}$ et al. (2006). These authors explained these data by the fact that all tested benzimidazoles have a common chemical structure; therefore, the bioconcentration factor can be estimated by a quantitative structure-activity relationship model based on the octanol-water partition coefficient and the lipophilicity parameter $\left(\log K_{\mathrm{ow}}\right.$ of FEN=3.93 (Mottier et al. 2003) and $\log K_{\text {ow }}$ of FLU $=2.91$ (Horvat et al. 2012)) could explain most of the observed toxicity to D. magna of the benzimidazoles as well as the difference in their toxicityFEN $\left(E_{50}=19 \mu \mathrm{g} \mathrm{L}^{-1}\right)$ occurred to be twice more toxic than FLU $\left(\mathrm{EC}_{50}=45 \mu \mathrm{g} \mathrm{L}^{-1}\right)$. 
Moreover, Escher highlights that about $60 \%$ of all industrial chemicals act as baseline toxicants so that they interfere with the membrane structure and functioning simply by partitioning into the membrane (Escher 2001). Only certain compounds may additionally exhibit more specific and selective mechanisms. Therefore, in our study, we also conducted additional calculations to verify if FLU and FEN act as a baseline toxicants - whether they have specific or nonspecific mode of action to non-target organisms. For this purpose, Eqs. 1, 2 and 3 ("Baseline toxicity") were employed (Escher and Hermens 2002). Equation 1 ("Baseline toxicity") refers to connection of $\log K_{\mathrm{mw}}$ with $\log K_{\mathrm{ow}}$ for polar compounds. Equation 2 is a QSARs of baseline toxicity based on $K_{\mathrm{mw}}$ as descriptor for D. magna. Equation 3 provides an information if the compound has specific mode of action or act as baseline toxicant (Escher et al. 2006). This parameter (TR) is the ratio of the predicted baseline effect concentration $\mathrm{EC}_{50}$ of a compound to the experimentally determined $\mathrm{EC}_{50}$. If TR is greater or equal than 10 , it can be assumed that the mode of action is specific; if these parameter is less than 10 , we are dealing with baseline toxicity. Data obtained in our investigation were as follows: $\mathrm{TR}_{\mathrm{FLU}}=341, \mathrm{TR}_{\mathrm{FEN}}=153$.

Since pharmaceuticals, as biologically active compounds, are designed to interact with a target molecule in the animal, in the environment they may affect other organisms having the same target or exert toxicity via other mechanisms (Gunnarsson et al. 2008). Different modes of benzimidazole action were reported. In studies with the parasite Trichuris globulosa, the anthelmintic effects of the benzimidazoles thiabendazole and fenbendazole were related to microtubule related process which is an inhibition of glucose uptake with resultant alterations in glucose metabolism (Jasra et al. 1990). Inhibition of amino peptidase activity and glutamate catabolism and increase in intracellular calcium levels were observed in Echinococcus granulosus protoscoleces after exposure to flubendazole (Cumino et al. 2009). In the in vitro studies with leukemia and myeloma cell lines, flubendazole induced cell death through mechanism related to alteration of microtubule structure and inhibited tubulin polymerization but, in contrast to the observation in parasite, alteration in glucose uptake was not observed (Spagnuolo et al. 2010). Moreover, at the genetic level changes in gene expression after $4 \mathrm{~h}$ of flubendazole treatment were observed, 196 genes were identified to be deregulated more than fourfold and 58 fell within eight functional annotations associated with chromosomal segregation and cytoskeleton regulation. Inhibition of tubulin polymerization can inhibit cell-cycle progression and induce mitotic catastrophe. It has been shown that flubendazole arrested cells in the $\mathrm{G} 2$ phase of the cell cycle and increased the number of multinucleated cells. On the basis of the performed experiments, it is hard to say which mechanism of action of the benzimidazoles caused adverse effects in test organisms and explain differences in their sensitivity to the studied pharmaceuticals. Since tubulin is found in both animal, plant and bacterial cells, it cannot be simply consistent with their effect as microtubule inhibitor. Hence, further more detailed studies are necessary.

\section{Conclusions}

As a result of our research, we have presented a comprehensive study revealing the ecotoxicity of two benzimidazoles (fenbendazole and flubendazole) to four different organisms, from which toxicity to duckweed (L. minor) and green algae (S. vacuolatus) has been tested for the first time. Studies concerning their ecotoxicity to $V$. fischeri and D. magna, although are in agreement with literature data, provide new insights thanks to the results from the chemical analysis and prove high reliability of the existing and newly obtained data. The most sensitive organism among the tested ones was D. magna (the $\mathrm{EC}_{50} 48 \mathrm{~h}$ values for FLU and FEN were $45 \mu \mathrm{g} \mathrm{L}^{-1}$ and $19 \mu \mathrm{g} \mathrm{L}^{-1}$, respectively). As the presence of the investigated drugs in the environment was confirmed in concentrations in the range of few nanogram per liter up to microgram per liter (Weiss et al. 2008; Van De Steene and Lambert 2008; Zrnčić et al. 2014), their toxicity to D. magna at the levels of microgram per liter might influence these organisms in the ecosystem. However, further investigation should be taken into consideration concerning chronic tests in longer period of time. Moreover, we have performed additional calculations and included a discussion focused on a possible explanation of the observed strong ecotoxicity (exhibiting a specific MoA) of these drugs to D. magna.

Acknowledgments The authors would like to acknowledge the financial support of the German Academic Exchange Service (DAAD) and National Science Centre under decision DEC-2011/03/B/NZ8/03009, Poland. The publication is financed by the European Social Fund in as a part of the project "Educators for the elite - integrated training program for $\mathrm{PhD}$ students, post-docs and professors as academic teachers at University of Gdansk" within the framework of Human Capital Operational Programme, Action IV. The authors are grateful to Ulrike BottinWeber, Stephanie Steudte and Juliane Filser for their support.

Open Access This article is distributed under the terms of the Creative Commons Attribution License which permits any use, distribution, and reproduction in any medium, provided the original author(s) and the source are credited.

\section{References}

Alexy R, Schöll A, Kümpel T, Kümmerer K (2004) What do we know about antibiotics in the environment? In: Kümmerer $\mathrm{K}$ Pharmaceuticals in the environment: sources, fate, effects, and risk, 2nd ed. Springer-Verlag Berlin Heidelberg, 209-221 
Altenburger R, Bödeker W, Faust M, Grimme LH (1990) Evaluation of the isobologram method for the assessment of mixtures of chemicals: Combination effect studies with pesticides in algal biotests. Ecotoxicol Environ Safe 20:98-114

Białk-Bielińska A, Stolte S, Arning J, Uebers U, Böschen A, Stepnowski P, Matzke M (2011) Ecotoxicity evaluation of selected sulfonamides. Chemosphere 85:928-933

Cleuvers M (2003) Aquatic ecotoxicity of pharmaceuticals including the assessment of combination effects. Toxicol Lett 142:185-194

Cumino AC, Elissondo MC, Denegri GM (2009) Flubendazole interferes with a wide spectrum of cell homeostatic mechanisms in Echinococcus granulosus protoscoleces. Parasitol Int 58:270-277

Danaher M, Howells LC, Crooks SRH, Cerkvenik-Flajs V, O'Keeffe M (2006) Review of methodology for the determination of macrocyclic lactone residues in biological matrices. J Chromatogr B 844:175203

DIN 38412-L34 (1991) Luminescence inhibition assay with Vibrio fischeri

Drost W, Matzke M, Backhaus T (2007) Heavy metal toxicity to Lemna minor: studies on the time dependence of growth inhibition and the recovery after exposure. Chemosphere 67:36-43

Escher B I, (2001) Molecular mechanisms in aquatic ecotoxicology: specific and non-specific membrane toxicity A habilitation thesis in environmental chemistry and ecotoxicology Zurich

Escher BI, Hermens JM (2002) Modes of action in ecotoxicology : their role in body burdens, species sensitivity, QSARs, and mixture effects. Environ Sci Technol 36:4201-4217

Escher BI, Behra R, Eggen RIL, Fent K (1997) Molecular mechanisms in ecotoxicology: an interplay between environmental chemistry and biology. CHIMIA Int J Chem 51:915-921

Escher BI, Bramaz N, Richter M, Lienert J (2006) Comparative ecotoxicological hazard assessment of beta-blockers and their human metabolites using a mode-of-action-based test battery and a QSAR approach. Environ Sci Technol 40:7402-7408

Faust M, Altenburger R, Backhaus T, Blanck H, Boedeker W, Gramatica P, Hamer V, Scholze M, Vighi M, Grimme LH (2001) Predicting the joint algal toxicity of multi-component $s$-triazine mixtures at low-effect concentrations of individual toxicants. Aquat Toxicol 56:13-32

García-Galán MJ, Silvia Díaz-Cruz M, Barceló D (2009) Combining chemical analysis and ecotoxicity to determine environmental exposure and to assess risk from sulfonamides. TrAC 28:804-819

Gunnarsson L, Jauhiainen A, Kristiansson E, Nerman O, Larsson DGJ (2008) Evolutionary conservation of human drug targets in organisms used for environmental risk assessments. Environ Sci Technol 42:5807-5813

Hoechst-Roussel Agri-Vet Company (1995) Environmental assessment: fenbendazole type A medicated article (premix) in dairy cattle of breeding age NADA $137-600$

Horvat AJM, Pavlović DM, Babić S, Ašperger D, Pelko S, Mance AD, Kaštelan-Macan M (2012) Analysis, occurrence and fate of anthelmintics and their transformation products in the environment. TrAC 31:6184

ISO Guideline 6341 (1996) Determination of the inhibition of the mobility of Daphnia magna Straus (Cladocera, Crustacea) - acute toxicity test

ISO Guideline 8692 (1989) Water quality-fresh water algal growth inhibition test with Scenedesmus subspicatus and Selenastrum capricornutum

Jasra N, Sanyal SN, Khera S (1990) Effect of thiabendazole and fenbendazole on glucose uptake and carbohydrate metabolism in Trichuris globulosa. Vet Parasitol 35:201-209

Kołodziejska M, Maszkowska J, Białk-Bielińska A, Steudte S, Kumirska J, Stepnowski P, Stolte S (2013) Aquatic toxicity of four veterinary drugs commonly applied in fish farming and animal husbandry. Chemosphere 92:1253-1259

Martin RJ (1997) Review modes of action of anthelmintic drugs. Vet J 154:11-34
MicroBioTest Inc., Daphtoxkit F (1996) Crustacean toxicity screening test for freshwater. Standard Operational Procedure 1-27

Migowska N, Caban M, Stepnowski P, Kumirska J (2012) Simultaneous analysis of non-steroidal anti-inflammatory drugs and estrogenic hormones in water and wastewater samples using gas chromatography-mass spectrometry and gas chromatography with electron capture detection. Sci Total Environ 441:77-88

Mottier ML, Alvarez LI, Pis MA, Lanusse CE (2003) Transtegumental diffusion of benzimidazole anthelmintics into Moniezia benedeni: correlation with their octanol-water partition coefficients. Exp Parasitol 103:1-7

Nobilis M, Jira T, Lísa M, Holčapek M, Szotáková B, Lamka J, Skálová L (2007) Achiral and chiral high-performance liquid chromatographic determination of flubendazole and it metabolites in biomatrices using UV photodiode-array and mass spectrometric detection. J Chromatogr A 1149:112-200

Oh SJ, Park J, Lee MJ, Park SY, Lee JH, Choi K (2006) Ecological hazard assessment of major veterinary benzimidazoles: acute and chronic toxicities to aquatic microbes and invertebrates. Environ Toxicol Chem 25:2221-2226

Organization for Economic Cooperation and Development (2004) OECD Guideline for testing chemicals: 202 Daphnia sp. Acute immobilisation test $1-14$

Palma P, Palma VL, Fernandes RM, Soares AMVM, Barbosa IR (2008) Acute toxicity of atrazine, endosulfan sulphate and chlorpyrifos to Vibrio fischeri, Thamnocephalus platyurus and Daphnia magna, Relative to their concentrations in surface waters from the Alentejo Region of Portugal. Bull Environ Contam Toxicol 81: 485-489

Park S, Choi K (2008) Hazard assessment of commonly used agricultural antibiotics on aquatic ecosystems. Ecotoxicology 17:526-538

Santana Rodríguez JJ, Torres Padrón ET, Aufartová J, Sosa Ferrera Z (2010) Benzimidazole fungicides in environmental samples: extraction and determination procedures. In: Carisse O Fungicides InTech, 305-324

Santos LHLM, Araújo AN, Fachini A, Pena A, Delerue-Matos C, Montenegro MCBSM (2010) Ecotoxicological aspects related to the presence of pharmaceuticals in the aquatic environment. J Hazard Mater 175:45-95

Spagnuolo PA, Hu J, Hurren R, Wang X, Gronda M, Sukhai MA, Di Meo A, Boss J, Ashali I, Beheshti Zavareh R, Fine N, Simpson CD, Sharmeen S, Rottapel R, Schimmer AD (2010) The antihelmintic flubendazole inhibits microtubule function through a mechanism distinct from Vinca alkaloids and displays preclinical activity in leukemia and myeloma. Blood J 115:4824-4833

Teodorović I, Knežević V, Tunić T, Cučak M, Lečić JN, Leovac A, Tumbas II (2012) Myriophyllum aquaticum versus Lemna minor: sensitivity and recovery potential after exposure to atrazine. Environ Toxicol Chem 31:417-426

Tišler T, Kožuh Eržen N (2006) Abamectin in aquatic environment. Ecotoxicology 15:495-502

Van De Steene JC, Lambert WE (2008) Validation of a solid-phase extraction and liquid chromatography-electrospray tandem mass spectrometric method for the determination of nine basic pharmaceuticals in wastewater and surface water samples. J Chromatogr A 1182:153-160

Weiss K, Schüssler W, Porzelt M (2008) Sulfamethazine and flubendazole in seepage water after the sprinkling of manured areas. Chemosphere 72:1292-1297

Wollenberger L, Halling-Sørensen B, Kusk KO (2000) Acute and chronic toxicity of veterinary antibiotics to Daphnia magna. Chemosphere 40:723-730

Zrnčić M, Gros M, Babić S, Kaštelan-Macan M, Barceló D, Petrović M (2014) Analysis of anthelmintics in surface water by ultra high performance liquid chromatography coupled to quadrupole linear ion trap tandem mass spectrometry. Chemosphere 99:224-232 